\title{
HOB IDENTIFICATION METHODS
}

\author{
Andrzej Piotrowski' \\ 1 Czestochowa University of Technology, Institute of Mechanical Technologies (ITM), Al. Armii Krajowej 21, 42- \\ 201 Częstochowa, Poland, e-mail: apiotr@itm.pcz.pl
}

Received: 2017.12.01

Accepted: 2018.02.01

Published: 2018.03.01

\begin{abstract}
In industrial practice, hobs are manufactured and used. The problem boils down to the identification of a hob with defining its profile, which depends on many design and technological parameters (such as the grinding wheel size, profile, type and positioning during machining). This makes the basis for the correct execution and sharpening of the tool. The accuracy of the hob determines the quality of gear wheel teeth being shaped. The article presents hob identification methods that are possible to be used in industrial and laboratory practice.
\end{abstract}

Keywords: hob, accuracy, technology, metrology, CMM

\section{INTRODUCTION}

In spite of the passage of time and a huge progress in toothing shaping technology, modular hobs continue to constitute the most popular technology for machining spur gears or helical gears, racks, splines, belt transmissions, etc. $[3,4]$. The automotive industry, in particular, uses huge quantities of modular hobs of an increased length and number of teeth on the rack (leaf hobs) (Fig. 1b) [6]. The development in the design of CNC machine tools has contributed to the construction of special, composite hobs possible to be used in traditional machine tools [16-19]. Hobs with replaceable plates are characterized by very good technological parameters, but lower accuracy compared to monolithic hobs. As a rule, these are hobs of classes B and A. In the case of the monolithic design, hobs in accuracy classes AA or AAA are standard. Machining with a hob with such accuracy makes it possible to shorten the technological process and make a gear wheel through the elimination of additional operations and treatments. Modular hobs are produced of special tool alloys. In the case of small-module hobs designed for machining hard-machinable materials and heavy duty machining, monolithic hobs are constructed, which are made of sintered carbides. As a rule, both types are additionally coated with layers that improve their machining properties and prolong the life of the hobs [6,16-19].

\section{THE GEOMETRY AND TECHNOLOGY OF HOB EXECUTION}

Hobs are among machining tools that are most difficult to design and make. Their geometry is very complex and requires the manufacturer to perform many technological operations and treatments. The most important hob elements are toothed bars which, in the machining process, form a technological gear with the gear wheel being machined $[2,10]$. As a result of hobbing, the rectilinear cutting edges of the hob form a characteristic, involute shape of the gear wheel tooth flank [3,4]. The classic hob is a backed-off tool (Fig. 1a) and has several to a dozen or so such toothed bars on its perimeter (depending on the module and diameter). Because of the helical tool nature, they are twisted and inclined at the lead angle $[2,10]$.

In the machining process, the hob forms a worm-gear wheel technological gear with the gear wheel being machined. The geometric analysis of so formed technological gear shows 
a)

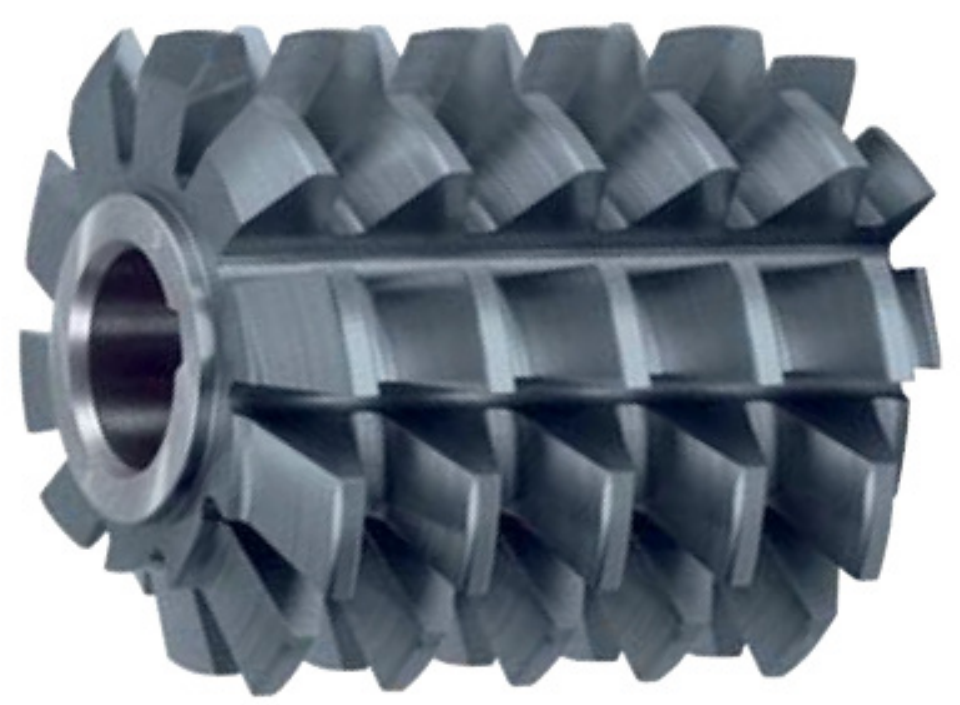

b)

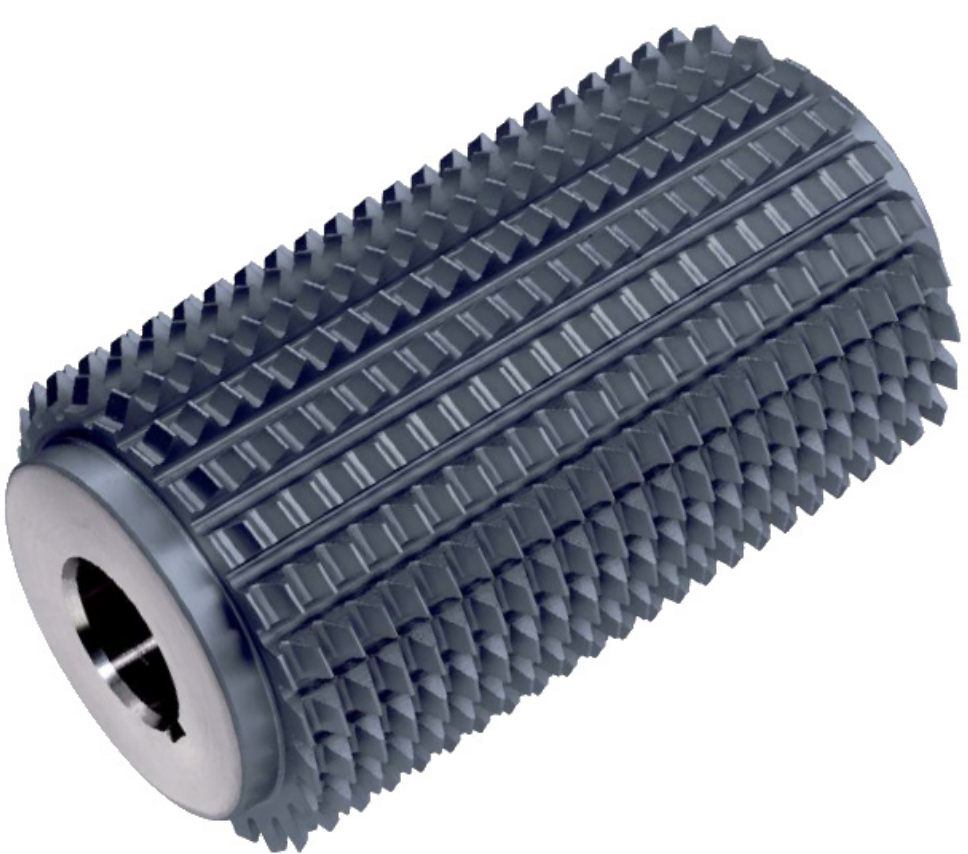

Fig. 1. Monolithic hobs; a) classic type, b) leaf type [6].

that the surface of the technological worm mating with the involute helical surface of the machined gear wheel should be an involute helical surface $[1,10]$.

The technological worm surface corresponds to the hob action surface, which is the locus of cutting edges. A cutting edge is formed by the intersection of the blade flank face with the rake face, whose form results from the technological process of hob blade shaping. For this reason, these surfaces determine the hob cutting edge profile and, as a consequence, the hob accuracy $[7,10]$. The involute helical surface is, on the other hand, a reference surface, with the profile of which the hob action surface profile can be compared. A characteristic feature of the involute helical surface is the section tangential to the base cylinder, which is rectilinear.

In the classic technological process, the side flank faces and the rake face intersecting them are repeatedly ground and measured. After taking measurements, the grinding wheels are dressed, and the next grinding of the blade surface is done. By the method of successive approximations, the manufacturer attains the assumed accuracy of the hob.

The "trial and error" method is replaced with the use of a mathematical, computer hob model. The hob is designed using a specialized software program. The calculation result is all 


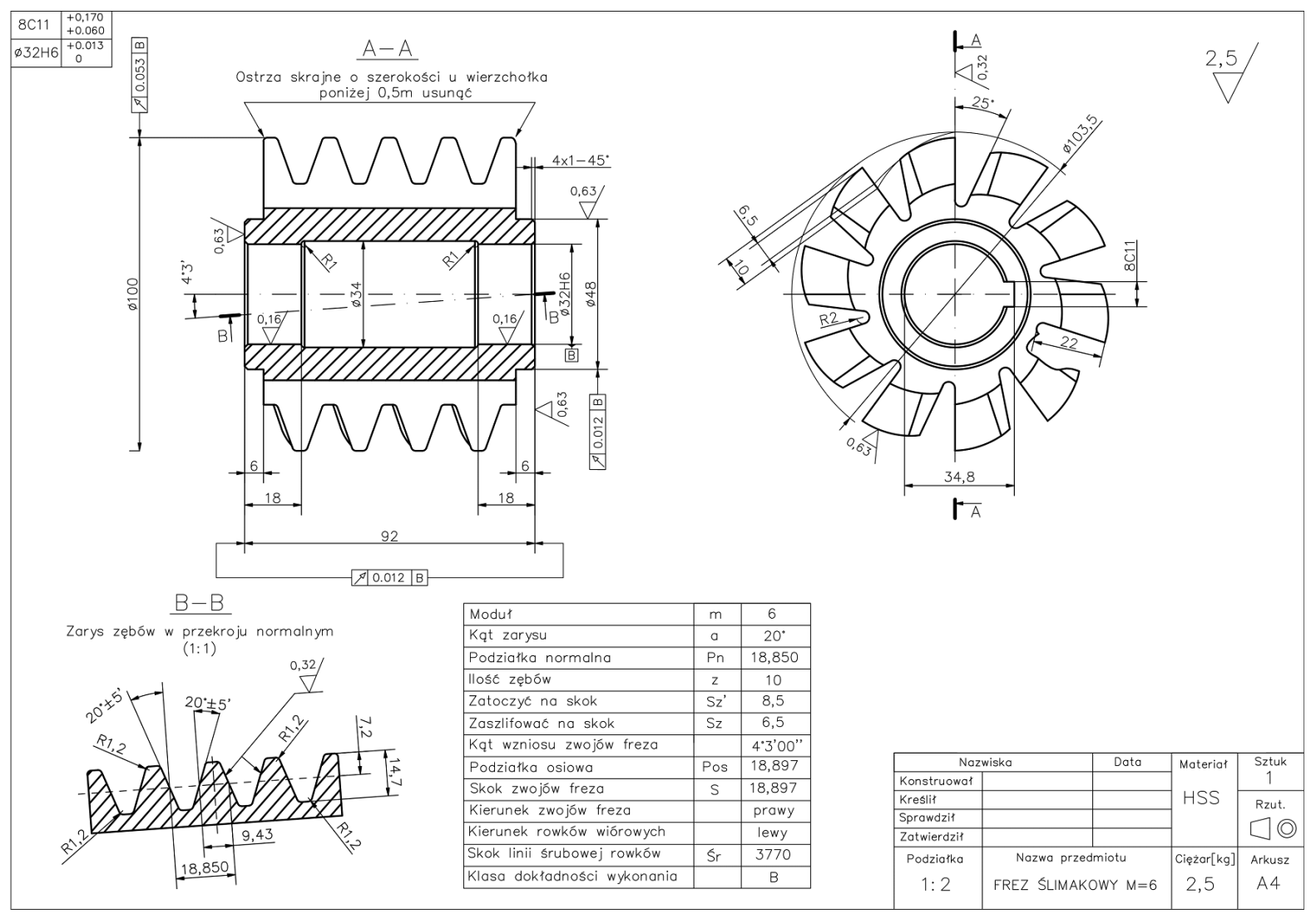

Fig. 2. The engineering drawing of a hob with a module of $\mathrm{m}=6$. (Author's elaboration)

tools' parameters and the program for forming (dressing) wormwheels for shaping hob surface . After having been made, the surfaces are measured and, if necessary, corrected based on the measurements' results. This implies that the hob measurement is an inseparable element of the technological process. The hob model is also used during the operation of the hob. The tool is subject to wear and, therefore, needs to be sharpened. In the process of sharpening, only the rake face is ground (the tool is backed off). The shape (profile) of the grinding wheel and its positioning relative to the rake surface being ground determine the correctness of the sharpening process $[5,10]$. The tool manufacturer does not provide information on the shape of the grinding wheel used for the final formation of the rake face. Therefore, before proceeding with sharpening, the hob should be identified by measuring its characteristic parameters. After the hob measurement, based on the developed mathematical model, the profile of the unilaterally-tapered disc-type grinding wheel and its positioning with respect to the tool to be sharpened can be calculated.

\section{ASSUMPTIONS AND THE EXAMINATION PROCEDURE}

When analyzing the technological process and operation of the hob, the measuring methods used in industry and in laboratories for the measurements and identification of the tool condition were compared. A classic, monolithic hob was used for the measurements (Table 1).

The hob selected for investigation was subjected to the sharpening process. The classic rake face grinding method relying on the tracer-finger, the master and the unilaterally-tapered disc-type grinding wheel sharpened along the straight line in the axial profile was used. Manual sharpening of the hob, repeated several times, was performed. By the performed operation, a situation typical of industrial conditions was simulated. The user of the hob operated it following the technological rules and subjected it to a regular sharpening process using commercially available grinding wheels designed for rake face grinding [11]. After several cycles of sharpening under workshop conditions, he handed the tool over to a specialized shop to be correctly sharpened $[2,5,10]$. Before 
Table 1. The hob - parameters.

\begin{tabular}{|c|l|c|c|c|}
\hline No. & \multicolumn{2}{|c|}{ Nominal } & Unit \\
\hline 1 & Module & $\mathrm{m}$ & 7 & $\mathrm{~mm}$ \\
\hline 2 & Total length & $\mathrm{D}_{\mathrm{a}}$ & 90 & $\mathrm{~mm}$ \\
\hline 3 & Working length & $\mathrm{D}_{\mathrm{r}}$ & 100 & $\mathrm{~mm}$ \\
\hline 4 & Nominal pitch & $\mathrm{P}_{\text {nom }}$ & 21.991 & $\mathrm{~mm}$ \\
\hline 5 & Tooth width on the pitch diameter & $\mathrm{B}_{z}$ & 10.995 & $\mathrm{~mm}$ \\
\hline 6 & Helix angle & $\mathrm{Y}$ & $4^{\circ} 29^{\prime}$ & ${ }^{\circ}$ \\
\hline 7 & Groove spiral lead & $\mathrm{S}_{\mathrm{r}}$ & 4208 & $\mathrm{~mm}$ \\
\hline 8 & Number of convolutions & & 5 & \\
\hline 9 & Helix direction & & right-hand & \\
\hline 10 & Number of cutting grooves & & 9 & \\
\hline
\end{tabular}

proceeding with sharpening of a hob whose actual parameters deviate from the nominal values, a series of measurements need to be performed to identify the hob. Classic, analogue measuring methods using a toolmaker's microscope and a hob measuring machine, and coordinate methods using coordinate measuring machines with a contact and a measuring (scanning) heads were chosen to carry out the task.

\section{Toolmaker's microscope measurements}

Notwithstanding the passage of time, one of the most common devices for hob identification in industrial conditions continues to be the large toolmaker's microscope (Fig. 3a) equipped with additional instrumentation to enable the correct positioning of the tool in the support. The hob is fixed on the shaft and then put in prisms located on the microscope table. The traditional goniometrical measuring head is used for measurements (Fig. 3b). The measurement is taken in passing light. The preliminary procedure involves the organoleptic assessment of the hob condition, reading out the nominal hob parameters from the nameplate, counting the number of teeth, determining the helix direction, counting the number of bars (grooves) and taking the measurement of geometrical parameters (length, diameter) by slide calliper or micrometric methods. On this basis, the operator calculates the remaining tool parameters.

Then, measurements were taken on the microscope to verify the hob conditions, providing a basis for the selection of the grinding method and calculation of the grinding wheel profile. The measurement results showed considerable deviations from the nominal values. The following were consistent with the factory parameters: the nominal pitch, $\mathrm{P}_{\text {nom }}=21.924 \mathrm{~mm}$; and the pitch diameter tooth width, $\mathrm{B}_{\mathrm{z}}=11.03 \mathrm{~mm}$. The helix angle, $\gamma=5^{\circ} 30^{\prime}$ (a difference of $1^{\circ}$ ), and the groove spiral lead, $\mathrm{S}_{\mathrm{r}}=3427 \mathrm{~mm}$ (a difference of $781 \mathrm{~mm}$ ), deviated significantly from the nominal values. The microscope does not allow the measurement of the cutting edge, only the assessment of its indentation. The measurements were taken at the Mikronar company of Radom, specializing in manufacturing and sharpening of machining tools. As a result of the performed identification, the company's workers disqualified the hob, recognizing it unfit to regenerate. No further measurements were taken.

\section{Analogue measuring machines}

In the 70 s of the 20 th century, special hob measuring machines were constructed. One of them, manufactured by Zeiss, is still part of the equipment of the Institute of Mechanical Technologies (ITM) at the Czestochowa University of Technology. The principle of operation of measuring machines relies on establishing the appropriate relation between the hob's rotary motion and the gauging point motion parallel its axis. In the Zeiss measuring machine, these motions are accomplished by a mechanical means (Fig. 4). The travel of measuring slide 4 causes gear wheel 5 to back off along rack 6 and, as a result, the rotation of the hob being measured (Fig. 2), whereas, the displacement of the slide between the extreme position corresponds to five rotations of the hob (five-convolution hob). Depending on the hob pitch, cradle 8 should be positioned so that the sensor tip moves in measuring column 7 by the value of five pitches with the appropriate measuring slide displacement between the extreme positions. Preparation for working, operation and taking measurements on the Zeiss machine are all carried out manually and are very time-consum- 
a)

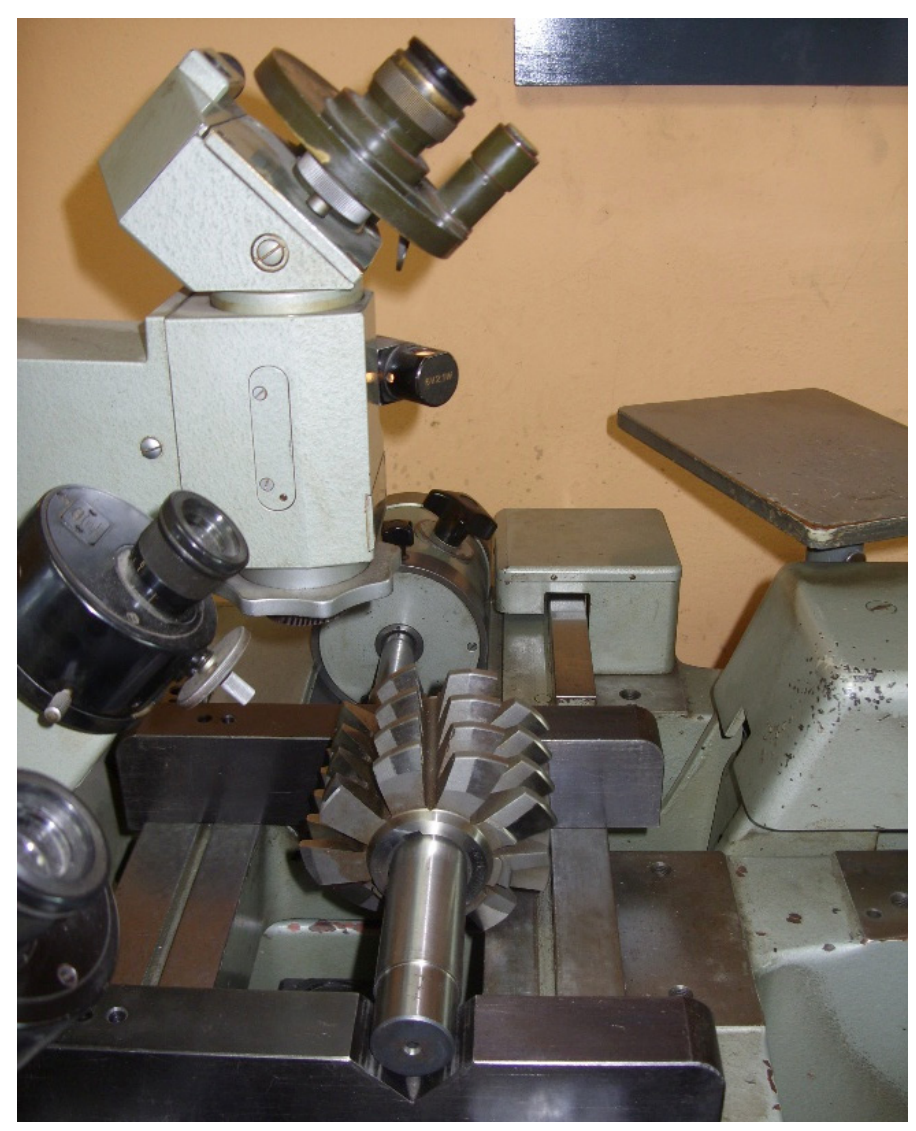

b)

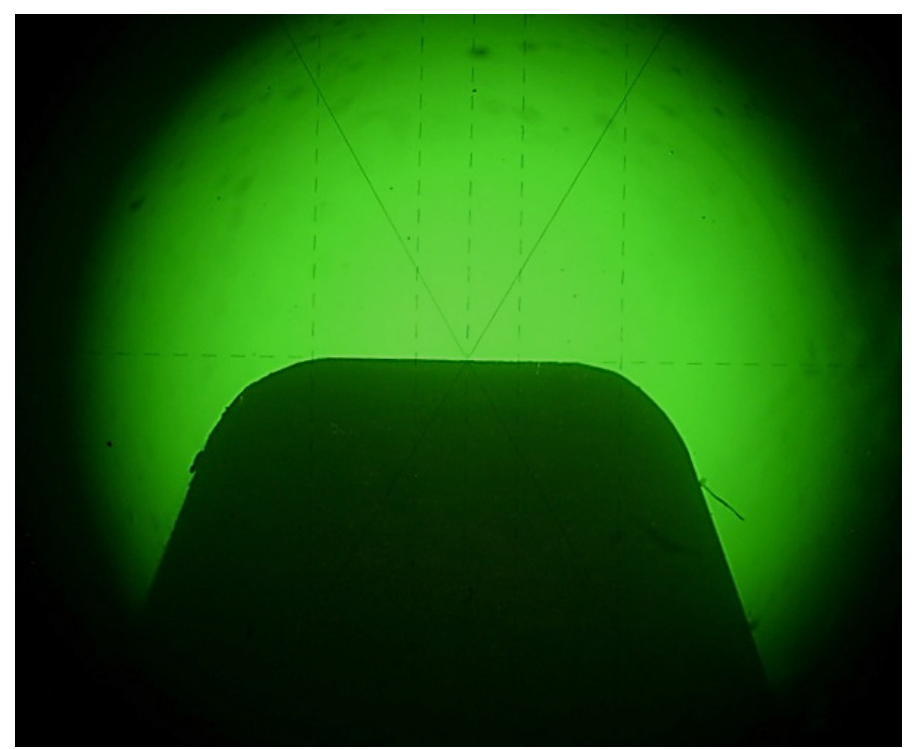

Fig. 3. A large toolmaker's microscope; a) hob fixture, b) measurement with the goniometric head.

(Author's elaboration)

ing. Recording the results takes place in an analogue manner using a special pen.

Using an induction sensor incorporated in rotary measuring column 7 , connected with the micrometric screw and equipped with a special gauging point, the measurements of the rake face rectilinearity (Fig. 5a), the shape of the side flank faces at a distance of $1 \mathrm{~mm}$ from the cutting edge, and the left-hand and right-hand cutting edge profiles (Fig. 5b) were taken. The measurement is very time-consuming and requires the operator to take measurements repeatedly, depending on the selected measuring length, with the measurement result being recorded on the measuring tape in a form of "peaks". Then, the manual identification, the numbering of "peaks" and their combination 


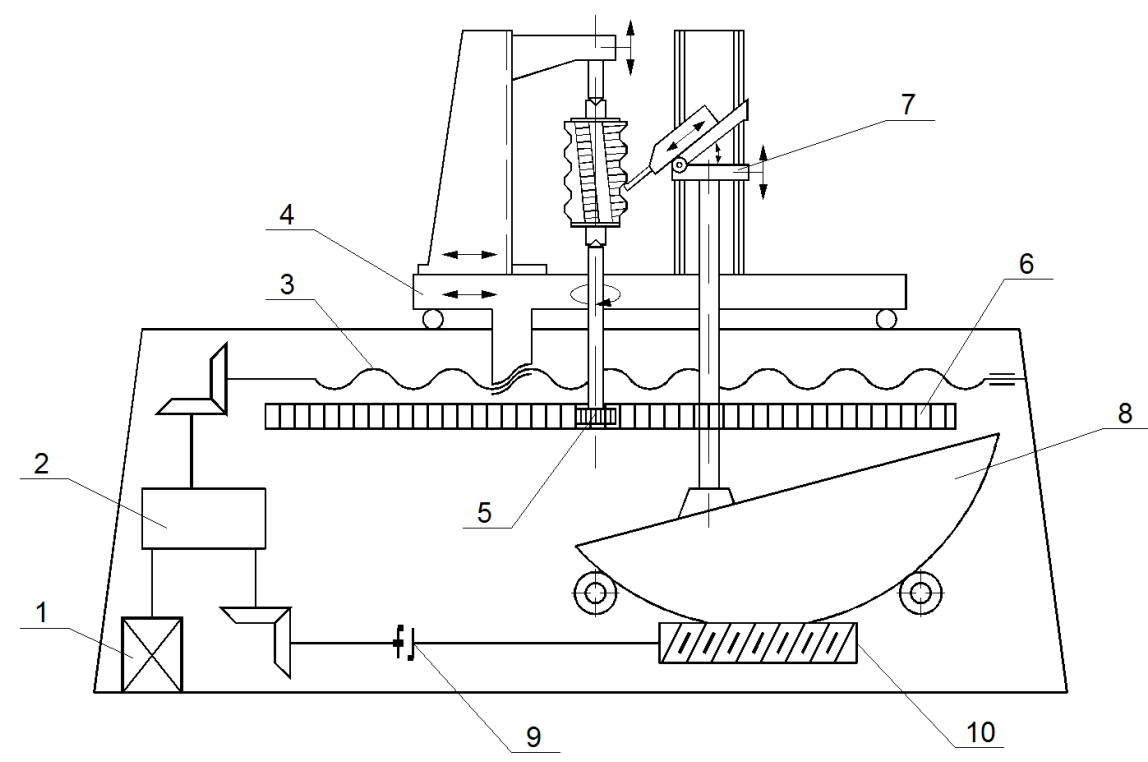

Fig. 4. A schematic diagram of the Zeiss machine for hobs: 1- motor, 2 - transmission, 3 - screw, 4 - measuring slide, 5 - gear wheel, 6 - rack, 7 - measuring column, 8 - cradle, 9 - coupling, 10 - worm. (Author's elaboration)

enable the cutting edge profile shape to be obtained. This method, due to the unavailability of the measuring tools, is used almost exclusively by hob manufacturers, and is extended by computerized recording that provides the capability to obtain the diagram of cutting edge deviations.

\section{Coordinate measuring methods}

The end of the 20th century was marked by an immense development of coordinate measuring methods. Computer controlled measuring machines, collecting a cloud of measuring ball centre position points, in many cases replaced analogue measuring methods. At present, coordinate measuring machines are available in many companies and are used for ongoing dimensional verification of manufactured products $[12,13]$. When analyzing the possibility of using coordinate methods for hob identification, a Zeiss WMM 850 complete with a Zeiss VAST XXT passive scanning head mounted on it was used in coordinate measuring method (CMM) measurements. An additional item of the machine equipment was a Zeiss RT 05-300 rotary table. The machine software consisted of the Zeiss Calypso, version 2015, and the Zeiss GEAR PRO HOB, version 2014, programs $[14,15]$. The measurement was performed at the Zeiss Measurement Centre in Mikołów.

In contrast to analogue methods, the coordinate measurement starts from building the mathematical model (coupled element) of the part to be measured. In the simplest case - a straight line, mathematically two, and metrologically three points lying on the straight line will suffice to build the model. On this basis, an idealized straight line model is built, with which measurement results will then be compared $[5,12,13,14]$. Deviations from ideal dimensions are presented in a form of easily interpreted diagrams. A metrologist can additionally determine the points deviating most from the nominal values (maximal deviations) in the graph. The main operation of comparing the graphs is carried out in the computer's operation memory [14].

Initial attempts to use coordinate machines for measuring hobs ended in failure. The building of the model caused a number of very serious problems to the programmers. Only in 2010, to Sandvik's order, Zeiss company extend the Zeiss Gear Pro gear wheel measuring program by adding a modular hob measuring module [15]. To operate with the program, a measuring machine equipped with a rotary table and featuring a measuring head is required. Theoretically, it is possible to use a contact head, but in that case the time of the measurements and its complexity (approach vectors) will increase several times. Due to the very complex geometry, the identification of the hob and, consequently, the building of the mathematical model of the hob requires the user to specify a very large number of parameters [15]. These shall conform to standard DIN 3968 or ISO $4468[8,9]$. The required quantities are identified organoleptically (the number of teeth, the number of grooves), read out from the nameplate or 
a)

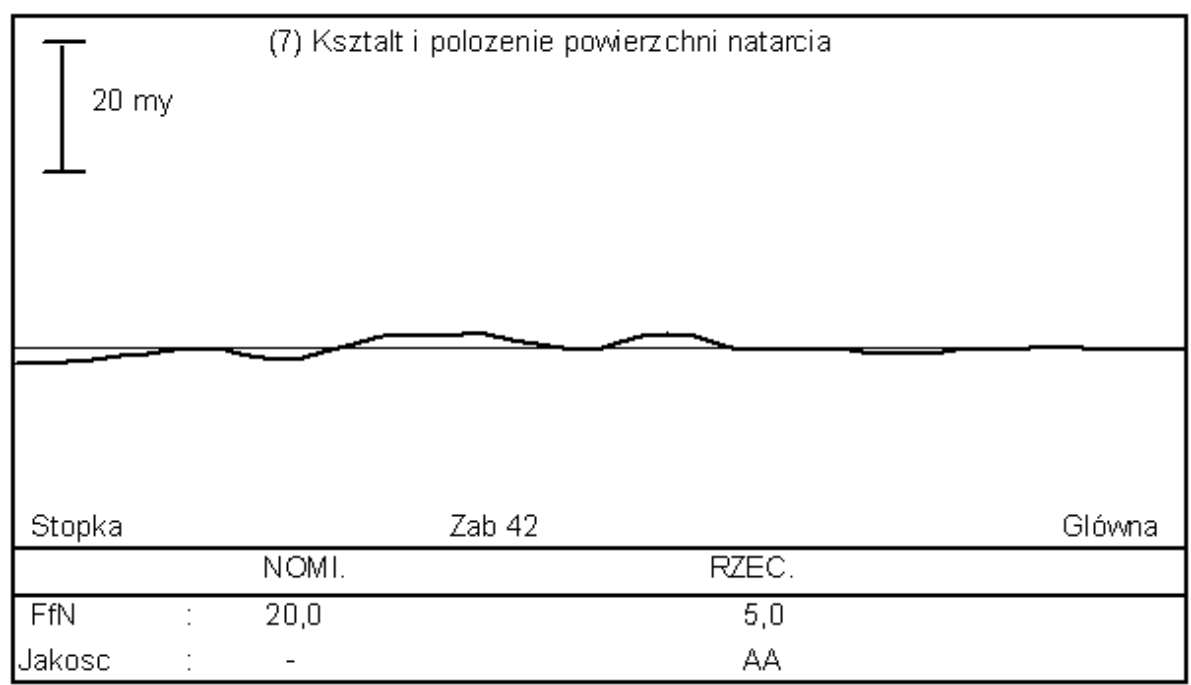

b)

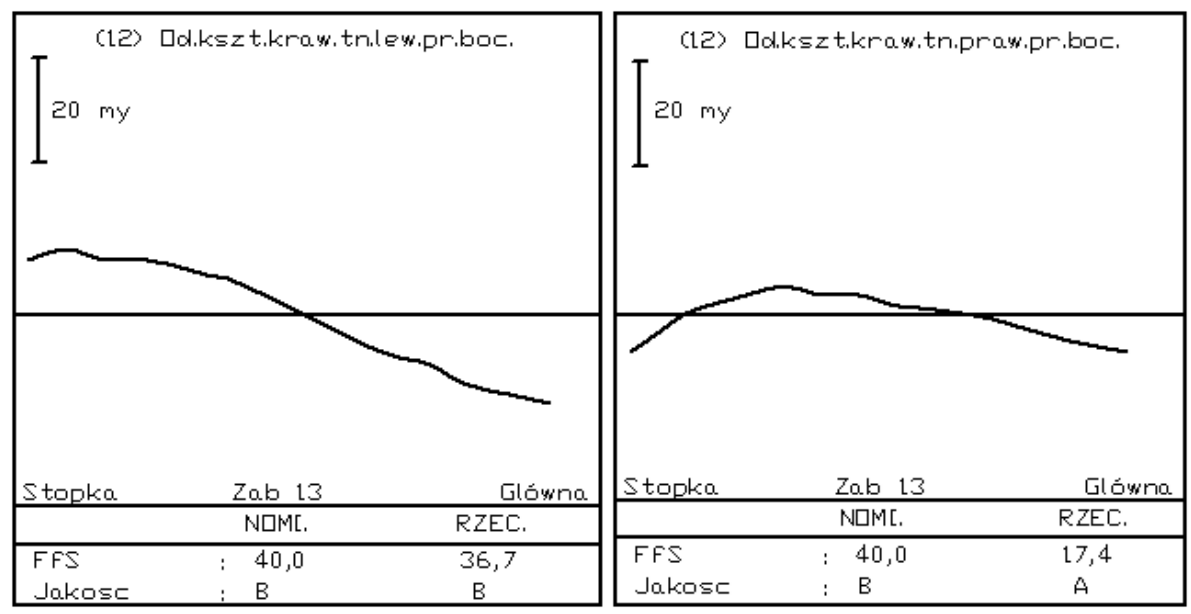

Fig. 5. The hob measuring machine. Measurement results: a) rake face, b) cutting edge profile.

(Author's elaboration)

preliminarily measured with a micrometer. They are entered in the dialogue windows of the Zeiss Gear Pro Hob program (Fig. 6). After entering the parameters, the program computes the remaining geometric quantities from the mathematical relationships [15].

The program is universal and enables the definition of special hobs with a rack profile modification (Fig. 7). The final result is the generation of a mathematical coupled element, that is the 3D hob model. It provides the basis for comparison with actual dimensions obtained from the measuring process. The Zeiss software stores both models - the reference model and the actual model obtained from the measuring procedure - in the memory $[14,15]$.

The next stage of hob identification is the definition of the measuring strategy that is the determination of the approach direction, the contact direction along with corrections, the approach mode, the tooth measurement range, the scanning range, the selection of the reference standard, the tolerance class, and the choice of the gauge plunger. The measurements were done with a gauging point ended with a $2 \mathrm{~mm}$-diameter ball.

The measuring procedure starts with the positioning of the gauging point above the surface to be measured. In the automatic mode, the gauging point moves towards the hob tooth point and comes into contact with the rake face. During the measurement, it moves down (towards the chip clearance). At the same time, the table makes a rotation, as a result of which the gauging point moves along a helix. As the measurement is taken, it moves over the rake face in parallel to the hob axis, at the pitch diameter height. Upon approaching the cutting edge, a drop takes place. The program records this moment and, using the mathematical ball radius compensation and the 3D hob model, computes the width of pitch 


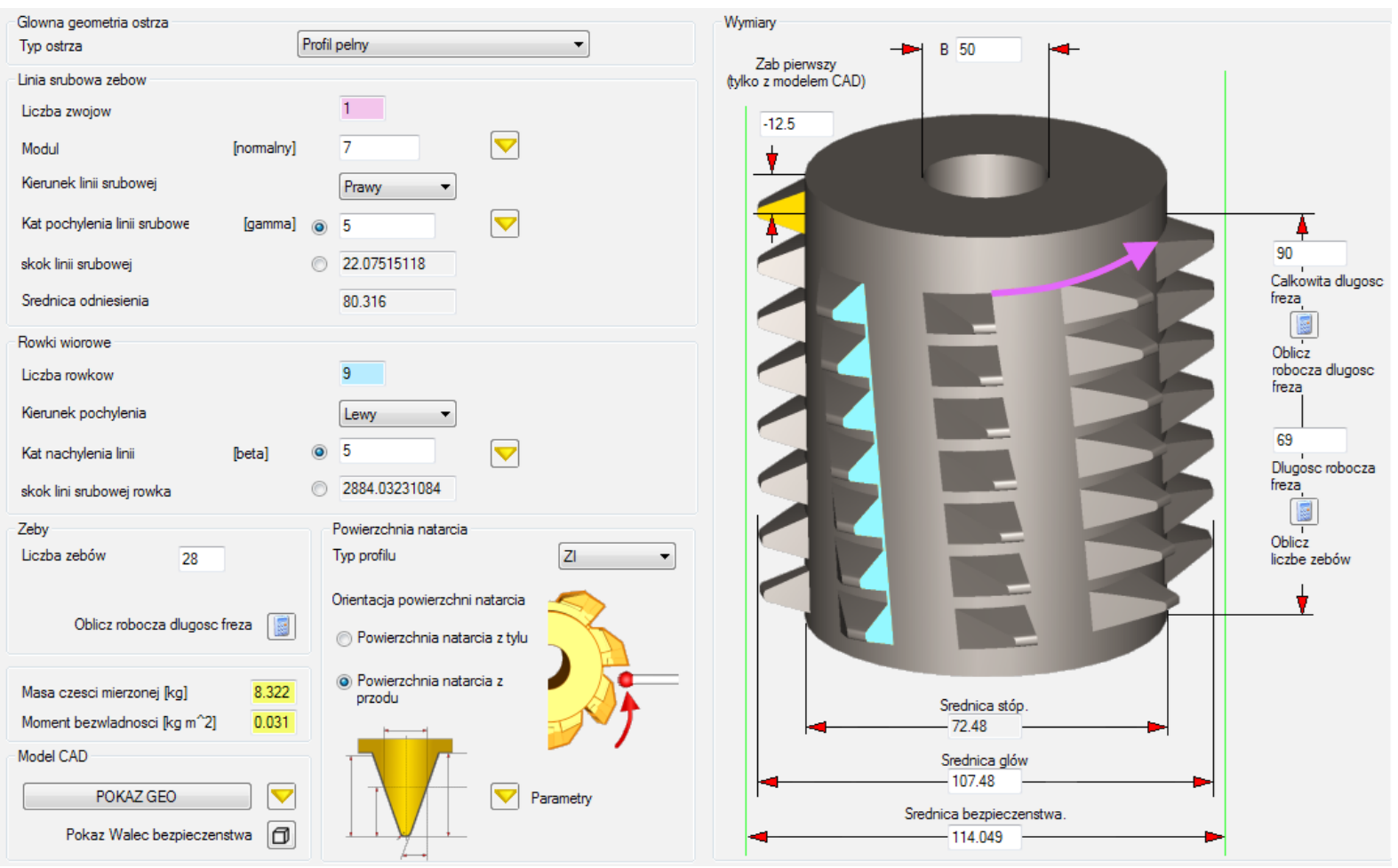

Fig. 6. The Zeiss GearPro HOB - the hob parameter input window. (Author's elaboration)

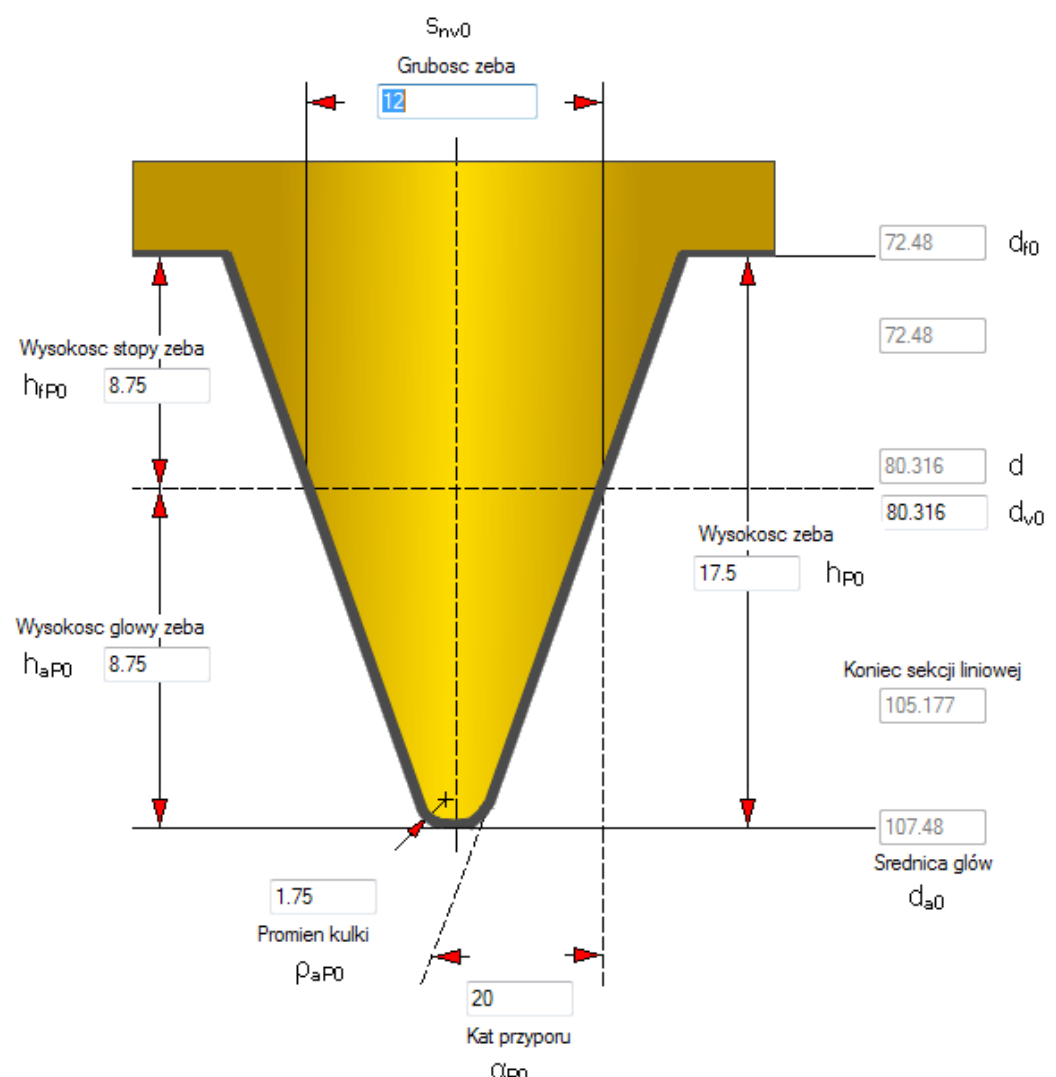

Profil skorygowany
$\square$ z protuberancja
$\square$ Odsuniecie flanki
Katy powierzchni skrawajacych
Pokaz

Srednica stóp

Poczatek sekcji liniowej

Srednica referencyja (obliczona)

Okrag odniesienia na rys.

- Obliczenia

bez korekcji promieniowej profilu nominalnego

$z$ korekcja promieniowa profilu

nominalnego przez roznice Dsred Dnom

$z$ korekcja promieniowa profilu nominalnego przez roznice Dmax

2 korekcja promieniowa profily (9) nominalnego przez roznice Da_ref i

$\alpha_{P O}$

Format wyswietlania

Srednica

Fig. 7. The Zeiss GearPro HOB - tooth model definition. (Author's elaboration) 
tooth diameter . Interestingly enough, the cutting edge position identification and pitch diameter tooth width measurement methods are identical to those for the classic analogue methods of hob measurement on dedicated machines.

During the course of the measurement it turned out that the head passed into the working travel mode at a varying distance from the tooth root, and upon measuring the upper cutting edge at the time when the gauging point was supposed to come into contact with the hob at the root diameter height, the machine detected a collision. The cause was the hob sharpening procedure carried out prior to the measurements. The large difference between the parameters preset in the software and the actual parameters resulted in the creation of a model, which significantly deviated from the true hob dimensions. Another obstacle was the fact of the automatic change of individual hob parameters during the course of entering some quantities, which was due to the $3 \mathrm{D}$ model building algorithm used by the programmers.

Knowing the incorrectly made hob correction, it was necessary to find parameters which are very close to the real ones. The greatest problem was to set the correct lead angle value. This angle should nominally amount to $4^{\circ} 29^{\prime}$, however, when taking analogue measurements a result of $5^{\circ} 30^{\prime}$ was obtained. It became necessary to use trials and errors and successive approximations to find a helix rake as close as possible to the real one. It turned out that the measurement was possible with the angle value defined at $5^{\circ}$, and the reduction of the root width and the range of diameters subject to assessment. After verifying the constructed 3D model, measurements were commenced. The measurement itself is wholly automatic and ends with the generation of very legible measurement reports (Fig. 8). The program measures several dozen hob parameters and enables the identification of practically all toot errors, including the classification of the tool into the respective class of accuracy.

When analyzing the measurement results, large discrepancies and a scatter relative to the nominal dimensions were found. Part of the hob parameters lay within Class A or AA, and the remaining parameters were contained within the a)

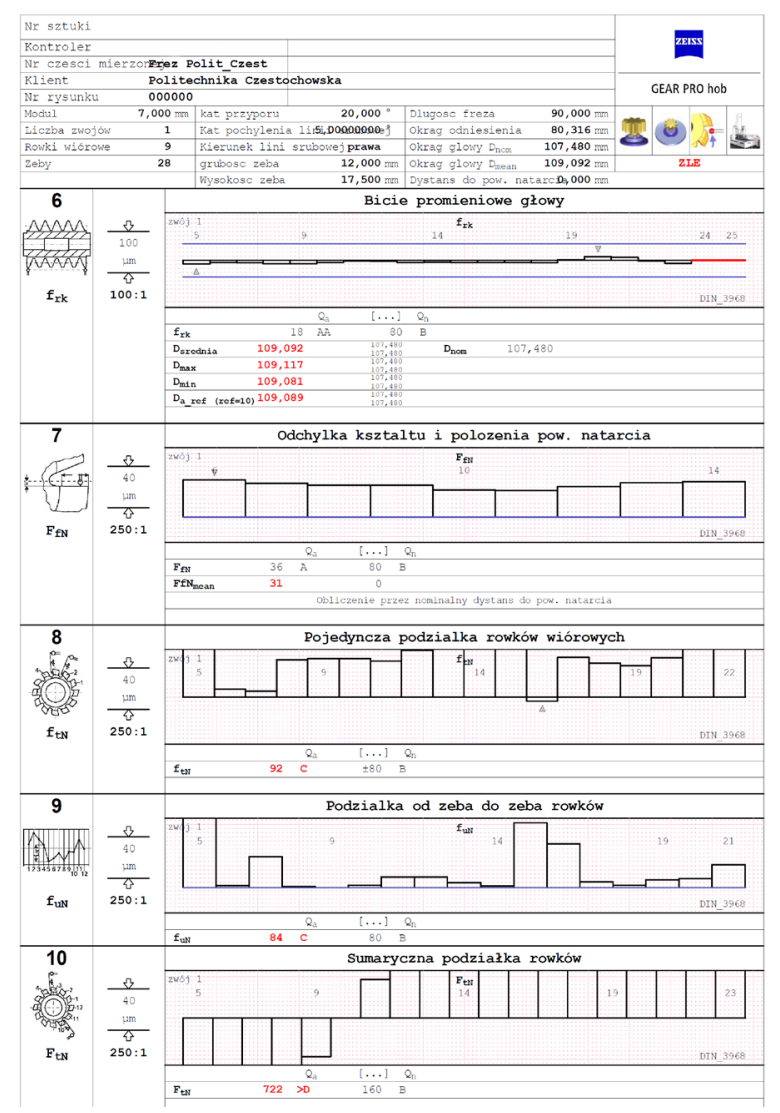

b)

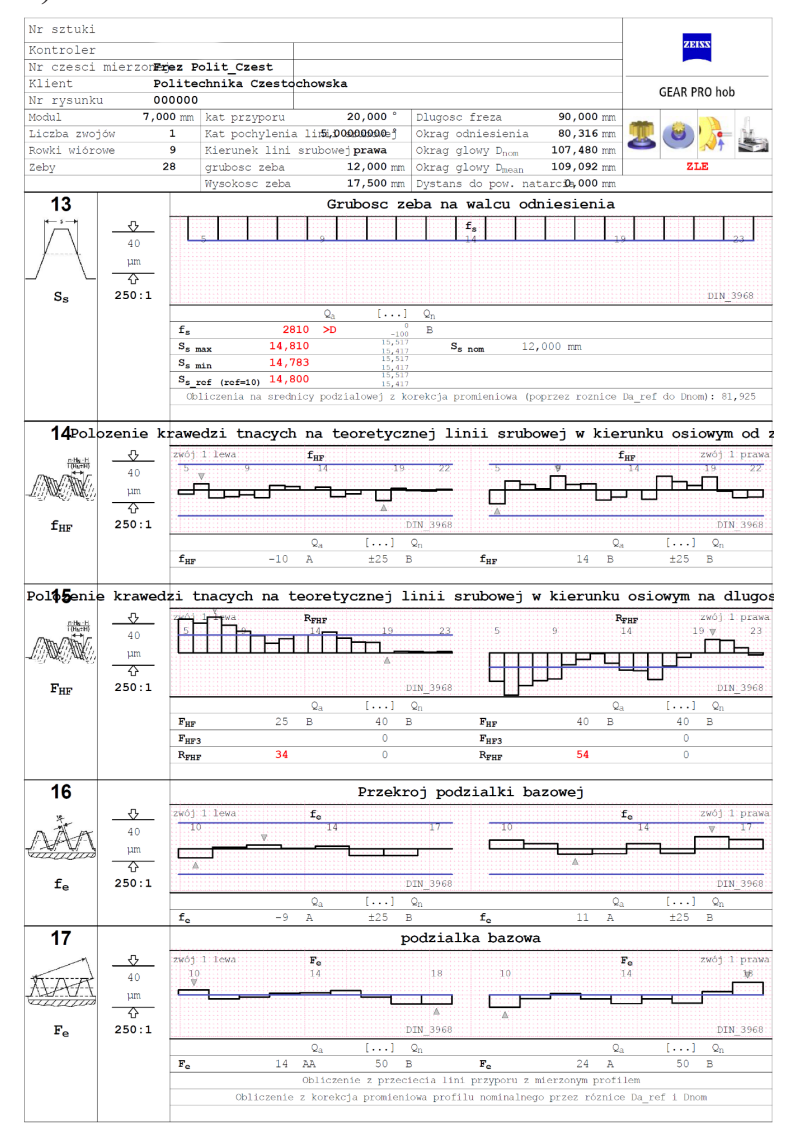

Fig. 8. The Zeiss GearPro HOB - measurement reports.

a) radial run-out, tooth pitch, b) tooth thickness, base pitch. (Author's elaboration) 
deviation limits characteristic of Class C. The largest error was observed for the lead angle of grooves over a length of $100 \mathrm{~mm}$. In spite of experimentally establishing the angle value at $5^{\circ}$, the diagram of deviations was totally incorrect (Fig. 9b). The analysis of the diagram showed that, in the grinding process, either the grinder incorrectly led the tracer-finger over the template, or, what is more likely, the template was not correct - the lead angle was different. The lead angle error resulted in an incorrect value of the pitch diameter tooth width. The nominal value resulting from calculation is $12 \mathrm{~mm}$, while the measured value is $14.2 \mathrm{~mm}$. The lead angle error has also an effect on many other hob parameters. Practically, consistent with the nominal values were deviations of tooth form profile (Fig. 9a). This was due to the fact that the hob is sharpened only along the rake face, and the both flank faces are formed by the manufacturers. The errors were contained within the limits of deviations for a hob of Class $\mathrm{B}$ (according to the nameplate). The measurement on the coordinate machine showed clearly that a rectilinear-profile grinding wheel had been used for rake face sharpening. A characteristic bulginess error is visible in the diagram (Fig. 9b).

The measurement reports enable a very accurate hob identification. Based on the diagram of the position and shape of the rake face, its error can be corrected by calculating the correct grinding wheel profile. A much more difficult problem is to uniquely identify and interpret the lead angle error. Practically, the only method of eliminating the error is by setting the grinding wheel according to the nominal value, and then performing grinding and a repeated measurement. To sum up, the measurement using a coordinate machine and specialized software is the most accurate and the fastest to take. The measurement accuracy is, however, dependent on the quality of the coupled element, that is the 3D model.

\section{CONCLUSIONS AND PRACTICAL RECOMMENDATIONS}

The basic aim of the investigation was to analyze the most popular methods of identification a)

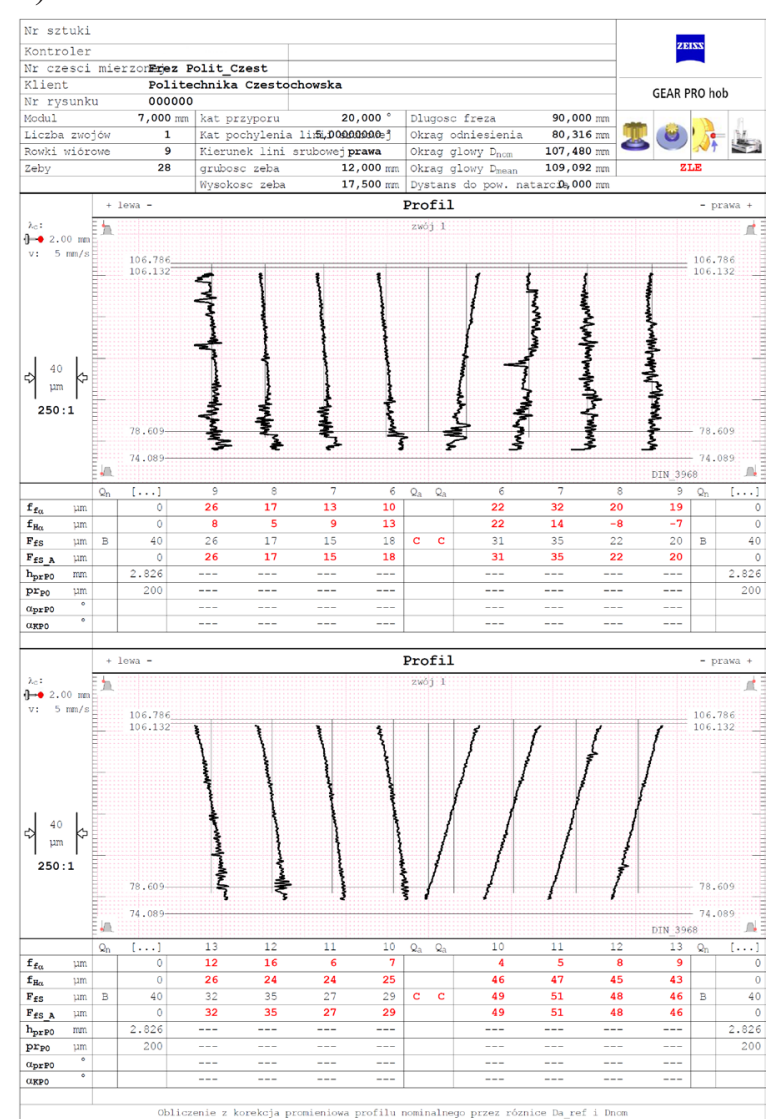

b)

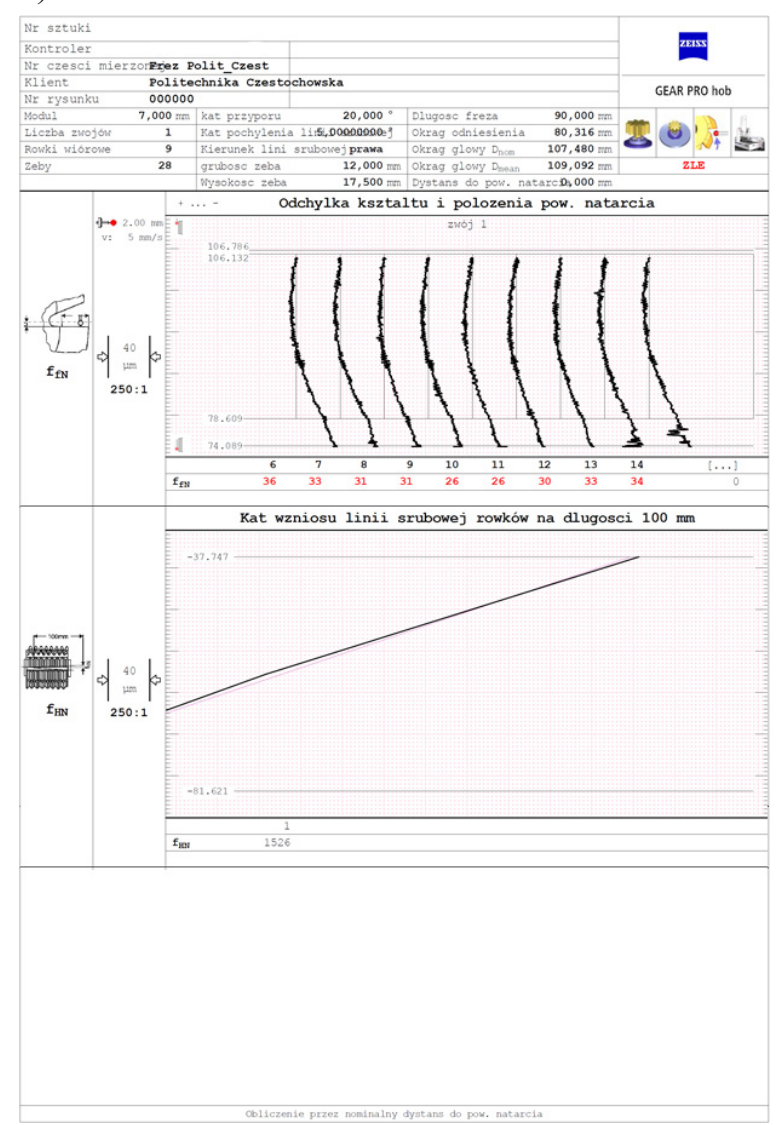

Fig. 9. The Zeiss GearPro HOB - measurement reports. a) tooth form, b) rake face rectilinearity (Author's elaboration) 
of hobs under laboratory and workshop conditions. A specially formed (incorrectly sharpened) hob allowed some problems to be discovered during measurements. A common feature of all measuring methods was a two-stage mode. The first stage consists of the visual and organoleptic assessment and analysis of the nominal features. In each case, the number of teeth, the number of chip clearances (toothed bars) and the number of convolutions need to be manually counted, the lead angle needs be read, and the tool surface quality (cutting edge indentation) needs to be assessed. The second step is dependent on the selected measuring method and boils down to the manual and automatic counting of the basic hob parameters dependent on the basic parameters, and the measurement of the hob.

When operating a hob, the user has a task to solve, which is opposite to that of the manufacturer's. On the basis of metrological analysis he has to define the shape (profile) and positioning of the rake face forming grinding wheel that is to build a model based on the measurements. The manufacturer first designs the hob - creates the 3D model in CAD programs, and on its basis, he plans the technological process. He can practically arbitrarily correct the profile of both flank faces and rake faces. The overriding goal is to obtain the correct cutting edge. Unfortunately, he does not specify the profile of the grinding wheel, with which he finally formed the rake face. The performed measurements allow the user to only roughly define this profile.

The easiest to interpret and most accurate are the measurement results obtained on the coordinate measuring machine using the Zeiss GearPro HOB software. This is a unique software application. The specially formed (erroneous) hob used in the investigation has starkly revealed the basic problem of coordinate measurements. This is the building of the coupled element, that is the $3 \mathrm{D}$ hob model. The results of measurements and the troubles encountered during taking them explicitly indicate the cause of the errors. Because the hob was incorrectly sharpened, both the lead angle and the rake face shape changed. By building the 3D model based on the nominal data, we obtain an incorrect tool shape and, as a consequence, the CMM movement control algorithm is erroneous and, in many instances, makes measurements impossible to take. The Zeiss GearPro HOB program does not measure the profile of the cutting edges that determine the hob accuracy.
It should be emphasized that the measurement results obtained by three different methods coincided. Even the simplest toolmaker's microscope enabled the correct identification of the hob. Unfortunately, it only allowed the measurement of the basic hob parameters. The analysis showed that the only instrument that allowed the cutting edge profile to be obtained, was the analogue hob measuring machine. Unfortunately, it is rarely found in industry, and the measurement process is long-lasting and requires trained personnel.

The basic, but the most important, conclusion resulting from the analysis of the hob identification methods is the postulate (requirement) that the tool manufacturer should provide additional tool data, and in particular the profile and the angle of positioning of the grinding wheel used for forming the rake face. This would result in an increase in the tool's life and an improvement of its accuracy during operation.

\section{REFERENCES}

1. Bouzakis K.D., Lili E., Michalidis N., Friderikos O.: Manufacturing of cylindrical gears by generating cutting processes: A critical synthesis of analytical methods, CIRP Annals - Manufacturing Technology 57, 2008, pp 676-696.

2. Cichosz P.: Narzędzia skrawające [Cutting tools], WNT Publishers, Warsaw 2006, 2013.

3. Dimitriou V., Antoniadis A.: CAD+based simulation of the hobbing process for the manufacturing of spur and helical gears. Int J Adv Manuf Technol 2009, 41, pp 347-357.

4. Dzierżkowski A.: Frezowanie obwiedniowe walcowych kół zębatych [Hobbing of spure gears], Scientific and Technical Publishers, Warsaw 1972.

5. Hulboj S.: Regeneracja i pomiary narzędzi skrawających [The regeneration and measurements of cutting tools], University Press of the Czestochowa University of Technology, Czestochowa 1997.

6. LMT Technology Group: Fette Gear Cutting Tools and Knowledge, Catalogue, www.lmt-tools.com, Germany 2017

7. Nieszporek T., Piotrowski A.: Enhancing the Accuracy of Composite Hobs, XXI Polish-Slovak Scientific Conference Machine Modeling and Simulations (MMS 2016), Hucisko, Polska 2016

8. Standard DIN 3968:1960-09: Tolerances for Single-start Hobs for Involute Spur Gears

9. Standard PN-ISO 4468:1999: Frezy ślimakowe jednokrotne do kół zębatych - Wymagania 
dokładności [Single hobs for gear wheels -- Quality requirements] (in Polish)

10. Piotrowski A.: Podwyższenie dokładności frezów ślimakowych modułowych [Enhancing the accuracy of modular hobs], Czestochowa University of Technology, Czestochowa 2002.

11. Piotrowski A.: Wpływ ostrzenia na dokładność frezów ślimakowych modułowych [The effect of sharpening on the accuracy of modular hobs], Mechanik, R.88/7, pp. 681-694, Warsaw 2015. (in Polish)

12. Ratajczak E., Woźniak A.: Współrzędnościowe systemy pomiarowe [The coordinate measuring systems], University Press of the Warsaw University of Technology, Warsaw 2016.

13. Ratajczak E.: Współrzędnościowa technika po- miarowa [The coordinate measuring technique], University Press of the Warsaw University of Technology, Warsaw 2005.

14.ZEISS: Calypso, The Program's User Manual, Zeiss, Germany 2014.

15. ZEISS: Gear Pro Hob, Instrukcja programu, Zeiss, Germany 2014.

16. http://3dcad.pl/aktualnosci/5797/coromill-176-skraca-czas-frezowania-kol-zebatych-o-polowe.html (in Polish) (may 2017)

17. http://www.sandvik.coromant.com/en-gb/products/coromill_172/Pages/default.aspx (may 2017)

18. http://www.sandvik.coromant.com/en-gb/products/coromill_176/Pages/default.aspx (may 2017)

19. http://www.sandvik.coromant.com/en-gb/products/coromill-177/Pages/default.aspx (may 2017) 